\title{
Journal of Power Sources
}

\author{
vol 203 (2012) p.135-139
}

DOI: http://dx.doi.org/10.1016/j.jpowsour.2011.12.023

\section{Influence of the diameter distribution on the rate capability of silicon nanowires for lithium-ion batteries}

\author{
Aurélien Gohier a, Barbara Laïk b,*, Jean-Pierre Pereira-Ramos b, Costel Sorin \\ Cojocaru a, Pierre Tran-Van c
}

a Laboratoire de Physique des Interfaces et des Couches Minces, École Polytechnique, Route de Saclay, 91128 Palaiseau Cedex, France

b Institut de Chimie et des Matériaux Paris-Est, ICMPE/GESMAT, UMR 7182 CNRS-UPEC, 2 à 8 rue Henry Dunant, 94320 Thiais, France

c Renault SAS, DREAM/DETA/SEE, 1, Avenue du Golf, 78288 Guyancourt, France

\begin{abstract}
For the first time, the effect of the nanowires diameter in terms of size and distribution on electrochemical properties of SiNWs grown by VLS was investigated. The diameter size was tuned by using three different gold catalyst film thicknesses. The crucial influence of this parameter is evidenced through comparison of the charge-discharge behavior and a study of the rate capability for the three samples. The rechargeable capacity as well as the rate capability is shown to be the best when the smallest diameters $(<65 \mathrm{~nm})$ are used compared to larger one $(<210 \mathrm{~nm}$ and $<490 \mathrm{~nm})$. High capacity values of $3500 \mathrm{mAh} \mathrm{g-1}$ are obtained for the smallest diameters at C/5 rate but still 2500, 1500 and $500 \mathrm{mAh}$ g- are recovered at C, $2.5 \mathrm{C}$ and $5 \mathrm{C}$. An excellent cycle life over 50 cycles is achieved at $1.3 \mathrm{C}$ with a capacity of $2500 \mathrm{mAh}$ g-1. This shows that by tailoring the diameter size and distribution, SiNWs can provide high power density anodes in lithium ion batteries.
\end{abstract}

Keywords: Silicon nanowires Lithium-ion batteries Negative electrode Rate capability Cycling performances

\section{Introduction}

Lithium-ion has become the most promising system for portable electronic devices, implantable devices and electric vehicles. Today, great efforts are being made to improve their energy density and to prolong their service life by optimizing new host materials for lithium insertion. Among anode materials, silicon is an attractive candidate since it presents the highest known theoretical charge capacity (3579 mAh g-1 at room temperature [1,2]), which is ten times higher than that exhibited by the conventional graphite elec- trode used for commercial application. However, Si-Li alloying process yields large volume change of silicon material, up to $~ 300 \%$ [3]. The mechanical stresses induced upon 
lithiation/delithiation cycles can thus lead to silicon mate- rial pulverization, resulting in a loss of electrical contact between particles and with the current collector and hence capacity fad- ing. One possible way to improve the silicon cycle life is to use architecture exhibiting significant surface/volume ratio in order to accommodate large structural strains. Thin film electrodes (2-D materials) have been evaluated to answer this requirement. How- ever, appreciable cyclability was only ensured with thickness lower than $250 \mathrm{~nm}[4,5]$.

Recently, a large variety of 1-D nanostructured silicon materials have attracted much attention for lithium-ion batteries applica- tions [6-14]. Silicon nanowires (SiNWs) have been widely studied since they can be directly grown on current collector $[9,12,15]$, thus providing good electronic contact. Their 1-D structure allows the electronic pathway to be efficient and to accommodate the large volume changes without cracking. Moreover, the need for binder or conducting additive is eliminated. Since pioneer works $[8,10,12]$, many studies have aimed to improve SiNWs based anodes performance by studying the effect of potential range for cycling [16], the nature of the collector [17] or silicon nanowires coat- ings $[13,18,19]$. Surprisingly, the effect of SiNWs diameter has never been studied as experimental parameter on cycling prop- erties while it is a crucial parameter which probably governs the available storage capacity, the rate capability and cyclability. Some rare authors mention the values of tested SiNWs diameters $[14,16,20]$ or more exactly the range in which SiNWs diameters can be found [8,21] without any comment about the real diameter distribution. Nevertheless, depending on processes and synthesis conditions (HF etching and CVD-VLS), SiNWs present various size with a length $-10 / \mathrm{J}-\mathrm{m}$ and diameter in the range $10-500 \mathrm{~nm}$. From this disparity, the question arises about the impact of SiNWs morphological features on their electrochemical behavior, and hence on anode performance. In other respects the disparity observed in electrochemical data reported on SiNWs probably originates from the wide dispersion in size diameter and length of the SiNWs. In this work, we investigate the effect of SiNWs diameter on the efficiency of electrochemical lithiation/delithiation process. We describe here the synthesis of three samples with $65 \mathrm{~nm}, 210 \mathrm{~nm}$ and $490 \mathrm{~nm}$ diameters prepared by the VLS method, by controlling the thickness of the gold film used as catalyst. Cycling performances and rate capability are especially investigated and we show the best results are obtained with the smallest diameters

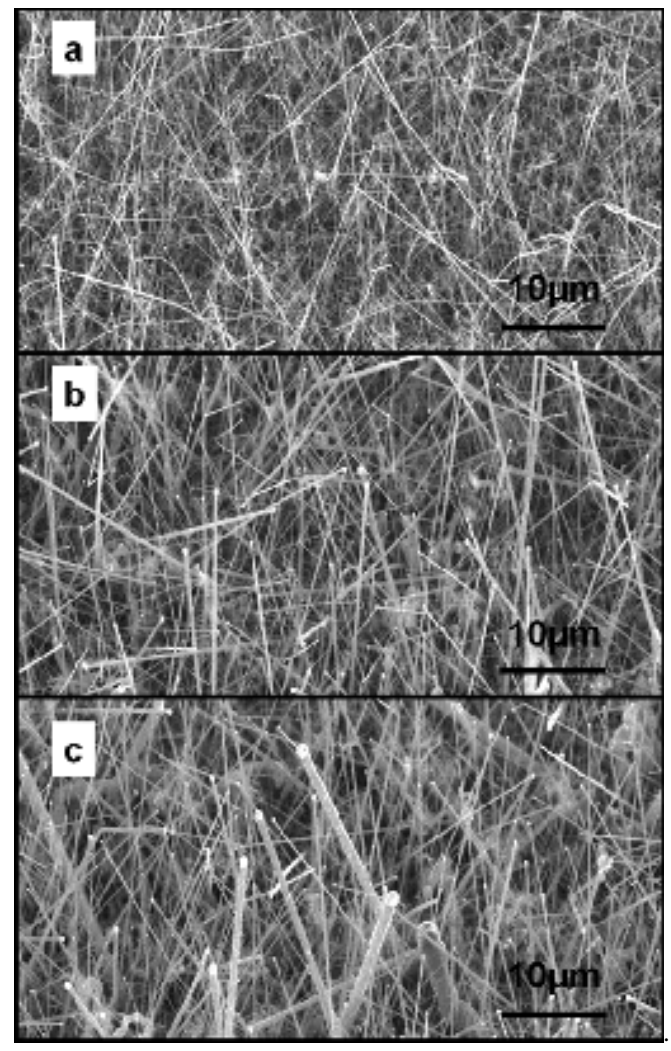

Fig. 1. Scanning Electron Microscopy images (tilt 45.) of silicon nanowires grown during 30 min on stainless steel foil using $3 \mathrm{~nm}$ (a), $10 \mathrm{~nm}$ (b) and $30 \mathrm{~nm}$ (c) thick films of gold as catalyst.

\section{Experimental}


Silicon NanoWires (SiNWs) were grown on 50 /J-m thick stain- less steel foils using Hot-Filament Chemical Vapour Deposition (HF-CVD). Steel substrates were copiously washed with acetone and isopropanol and then covered by thin films of gold $(\leq 30 \mathrm{~nm})$ using e-beam evaporator. CVD synthesis operated at $540{ }^{\circ} \mathrm{C}$ and $7.5 \mathrm{mbar}$ using $\mathrm{SiH} 4 / \mathrm{H} 2(50$ sccm for both gas) mixture as precur- sor. Gold covered substrates were directly introduced in the growth atmosphere during $30 \mathrm{~min}$. At the early stage of the process, gold thin film cracks and forms catalyst particles onto which SiNWs nucleate and grow. The size of gold catalyst clusters determine the diameters of the resulting SiNWs and these can be tuned by playing with the initial gold thickness as shown in the follow- ing section. Three sets of thin gold films were used to perform the SiNWs growth. They are characterized, using a quartz crystal microbalance, by a thickness of $3 \mathrm{~nm}, 10 \mathrm{~nm}$ and $30 \mathrm{~nm}$. Electrochemical studies were carried out in a two-electrode cell (Swagelok ${ }^{\circledR}$ type) fabricated out of SiNWs directly grown on the metallic current collector substrate as working electrode and lithium metal foil as both reference and counter electrode, as described in detail elsewhere [9]. No binders or conduct- ing carbon was used. The electrolyte was a commercial solution of 1 mol L-1 LiPF6 in dimethylcarbonate (LP30) obtained from Merck. Galvanostatic measurements were recorded using VMP3 apparatus (Biologic ${ }^{\circledR}$ ). A constant current density was used for lithiation/delithiation experiments. The charge/discharge rate is calculated based on the theoretical maximal insertion, at room temperature, of 3.75 $\mathrm{Li}$ ions for one $\mathrm{Si}$ atom, corresponding to $1 \mathrm{C}=3.58 \mathrm{~A} \mathrm{~g}-1$.

\section{Results and discussion}

The growth of Silicon NanoWires (SiNWs) using Hot-Filament Chemical Vapour Deposition (HF-CVD) technique requires the adjustment of numerous experimental parameters to obtain the desired SiNWs characteristics. Among them, it can be cited without being exhaustive working pressure, temperature, $\mathrm{SiH} 4$ flow rate, $\mathrm{SiH} 4 / \mathrm{H} 2$ ratio, substrate nature, thickness or pre-treatment. For- mer studies devoted to the optimization of these parameters led us to operate at $540{ }^{\circ} \mathrm{C}$ and 7.5 mbar using $\mathrm{SiH} 4 / \mathrm{H} 2$ (50 sccm for both gas) mixture as precursor. The substrate is made of stainless steel because it does not alloy with lithium and allows a satisfactory shaping of catalyst clusters. A thickness of $50 / \mathrm{J}$-m is chosen so that the sample can be cut, without being deformed under the influence of the heat. At least, as gold is known to be the more efficient cat- alyst and as the electrochemical contribution of the gold droplets still present at the top of the silicon wires after synthesis is minor [10], thin film of gold is used for the preparation of the samples. At the early stage of the process, the continuous gold film is transformed into three-dimensional clusters under temperature effect. The initial gold film thickness has an impact on the Au- clusters size distribution, and the diameter of resulting SiNWs grown by Vapor Liquid Solid (VLS) method is dependent on the Au-particles size. Hence, the thicker the gold thin film used for the synthesis, the larger the diameter of the SiNWs. Then, in order to compare the effect of the SiNWs diameter on anode performance, a set of three samples with significant differences in terms of diame- ter distribution were prepared. For this purpose, we used catalytic thin films of gold with various thicknesses, namely $3 \mathrm{~nm}, 10 \mathrm{~nm}$ and $30 \mathrm{~nm}$. After being heated under vacuum above the $\mathrm{Au}-\mathrm{Si}$ eutec- tic melting temperature $\left(540{ }^{\circ} \mathrm{C}\right), \mathrm{SiH} 4$ diluted in $\mathrm{H} 2$ is injected in the furnace for $30 \mathrm{~min}$. As expected and already presented else- where [9,10], an uniform carpet of wires that exhibits length up to $50 / \mathrm{J}$ $\mathrm{m}$, covers the substrate. Both X-ray diffraction (XRD) pattern and Raman spectrum of the samples confirm silicon crystallinity. The comparison of SEM images obtained for the three samples (Fig. 1) enables to confirm that a difference in the SiNWs diame- ter distribution is achieved for each sample. Indeed, the thicker the film from $3 \mathrm{~nm}$ (Fig. 1a) to 10 $\mathrm{nm}$ (Fig. 1b) and $30 \mathrm{~nm}$ (Fig. 1c), the larger the diameters of the wires. With the aim to finely estimate SiNWs diameter distribution and assuming in each case, diameter does not increase in time, the growth of a new set of samples was stopped after $13 \mathrm{~min}$. In this way, all SiNWs can be distinguished by SEM, counted, individually measured in diameter in order to estimate their weights and to be taken into account in the statistics. For the three samples, the diameters take values scattered in a range, all the wider as the film is thick. To illustrate this result, the cumulative weight of silicon nanowires is shown in Fig. 2 as a function of the wires diameters. For instance, when the gold thickness is about $3 \mathrm{~nm}$ (black data in the figure), $80 \mathrm{wt} \%$ of the silicon material correspond to wires with diameter size $<65 \mathrm{~nm}$. Besides, $50 \mathrm{wt} \%$ of the silicon correspond to wires with diameter lower than $40 \mathrm{~nm}$ whereas the other $50 \mathrm{wt} \%$ are spread between 40 and $120 \mathrm{~nm}$. For sample 2 and sample 3, when 10 or $30 \mathrm{~nm}$ of gold were used, those diameter values are significantly higher (Table 1). In the following of the paper, samples will be named by the value obtained when $80 \mathrm{wt} \%$ of silicon are reached, namely $65 \mathrm{~nm}, 210 \mathrm{~nm}$ and $490 \mathrm{~nm}$ for $3 \mathrm{~nm}, 10 \mathrm{~nm}$ and $30 \mathrm{~nm}$ of gold film thickness respectively. The electrochemical properties of the SiNWs as a function of their diameters have been investigated by galvanostatic cycling experiments with cutoff voltages of $0.02 \mathrm{~V}$ and $3 \mathrm{~V}$ vs. $\mathrm{Li}+/ \mathrm{Li}$. The first typical cycle and the second lithiation step obtained at $\mathrm{C} / 10$ rate are displayed in Fig. 3. The profiles presented in Fig. 3a and recorded for the thinnest diameters (65 nm, sample 1) are consistent with previous stud- ies. Indeed, the first charge (lithiation) exhibits a long flat plateau located at around $0.1 \mathrm{~V}$ corresponding to a lithiated silicon com- pound formed from crystalline silicon. For higher potentials, the electrochemical processes mainly involve the Solid Electrolyte Interphase (SEI) formation that is responsible of a substantial irre- versible capacity. Subsequent charges are different from the first one but look the same: in accordance with the literature, there are 
two alloying steps at around $0.2 \mathrm{~V}$ and $0.1 \mathrm{~V}$ respectively assigned to lithiation of amorphous and crystalline silicon $[8,11,22]$. The contri- bution at higher potential is henceforth minor, even if SEI is thought to be formed constantly during the cycles [23-25]. Whatever the cycle, the discharge step (dealloying) retains the same profile, with a single plateau at around $450 \mathrm{mV}$ corresponding to the delithiation into amorphous silicon [23]. Moreover, in this case, the hysteresis between charge and discharge curves is about only $300 \mathrm{mV}$ which makes silicon a material with an attractive working potential. The shape of the cycling curves obtained in the same experi- mental conditions, with thicker diameters, namely $210 \mathrm{~nm}$ (Fig. 3b) and $490 \mathrm{~nm}$ (Fig. 3c), are totally similar, but capacities are shown to strongly depend on diameter: the smaller the diameter, the higher the specific capacity. Indeed the first lithiation capacity was $5698 \mathrm{mAh} \mathrm{g-1,} 3678 \mathrm{mAh}$ g-1 and $3681 \mathrm{mAh} \mathrm{g}-1$ for diameters of $65 \mathrm{~nm}, 210 \mathrm{~nm}$ and $490 \mathrm{~nm}$ respectively. For the three samples, delithiation capacity is sharply lower (3720 mAh g-1 , $2593 \mathrm{mAh} \mathrm{g-1}$ and $1806 \mathrm{mAh} \mathrm{g-1} \mathrm{for} 65 \mathrm{~nm}, 210 \mathrm{~nm}$ and $490 \mathrm{~nm}$ respectively), revealing quite high irreversible capacity. The lithiation process in the second cycles show the same trend as observed in first cycles since the capacity increases as a function of diameter with $3500 \mathrm{mAh} \mathrm{g-1,} 2667 \mathrm{mAh}$ g-1 and $2380 \mathrm{mAh} \mathrm{g}-1$ for respectively samples 1, 2 and 3. However, the irreversible capacity is consider- ably reduced from the second cycle, suggesting that SEI formation mainly occurs during the first reduction step at a C/10 rate. One may note that irreversible capacity gets higher when decreasing the SiNWs diameter due to the correlative increase of active surface area.

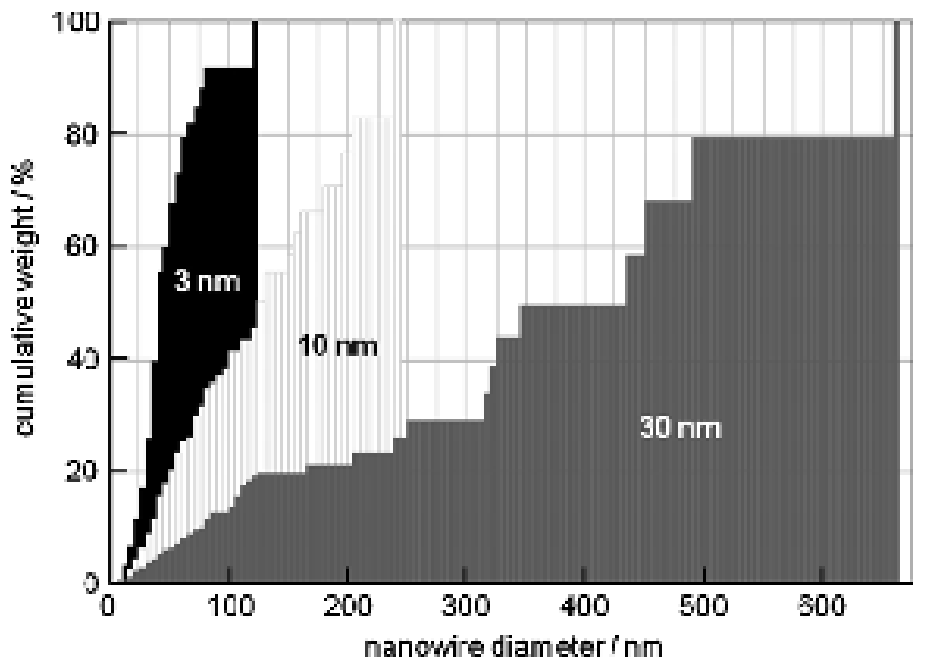

Fig. 2. Histograms of cumulative weight of silicon nanowires as a function of the initial gold thin film thickness (black: $3 \mathrm{~nm}$; white: $10 \mathrm{~nm}$; gray: $30 \mathrm{~nm}$ )

\begin{tabular}{lcc}
\hline SiNWs diameter, $\mathrm{nm}$ & $80 \mathrm{wt} \%$ & $50 \mathrm{wt} \%$ \\
\hline Sample 1 & 65 & 40 \\
Sample 2 & 210 & 130 \\
Sample 3 & 490 & 345 \\
\hline
\end{tabular}



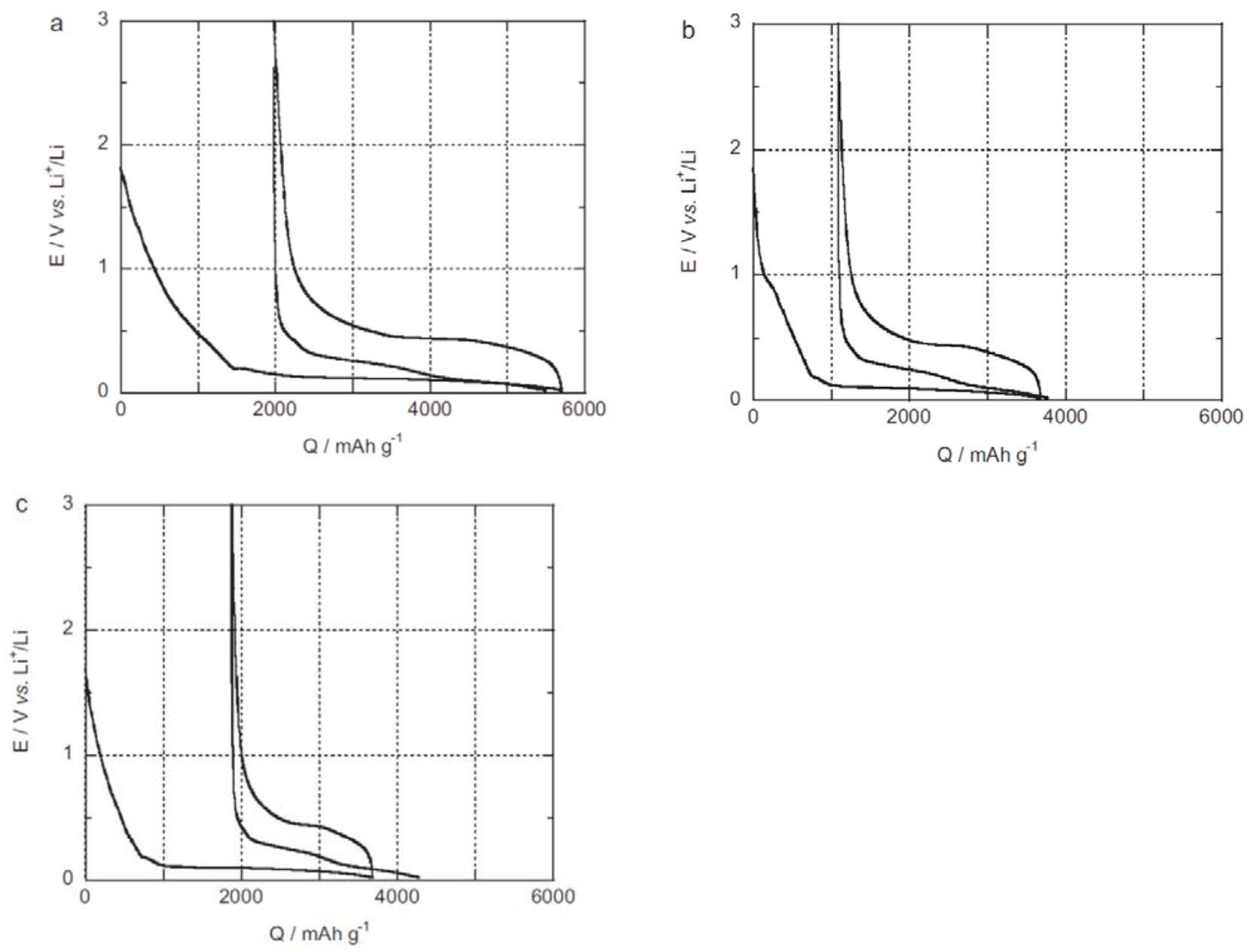

Fig. 3. Voltage profiles of the first cycle and second lithiation step at C/10 as a func- tion of SiNWs diameter distribution (respectively (a), (b) and (c) for sample 1, 2 and 3).

\begin{tabular}{|c|c|c|c|c|}
\hline \multicolumn{2}{|c|}{ Q, mAhg $\mathrm{g}^{-1}$} & \multirow[t]{2}{*}{ First lithiation } & \multirow[t]{2}{*}{ First delithiation } & \multirow[t]{2}{*}{ Second lithiation } \\
\hline Sample & $\varnothing, \mathrm{nm}$ & & & \\
\hline 1 & 65 & 5698 & 3720 & 3500 \\
\hline 2 & 210 & 3678 & 2593 & 2667 \\
\hline 3 & 490 & 3681 & 1806 & 2380 \\
\hline
\end{tabular}

Table 2 Specific capacities at C/10 rate as a function of SiNWs diameter distribution.

As shown above, only small diameter SiNWs (65 nm) exhibit high specific lithiation capacity (3500 mAh g-1 ) close to theoretical value (3580 mAh g-1) at C/10 rate. Using larger diameter SiNWs, capacities do not exceed $2600 \mathrm{mAh} \mathrm{g-1}$ at same rate (Table 2). We assume that this significant difference is due to the shorter diffusion pathway which in the case of smallest diameters probably allows a quantitative lithiation of small diameter SiNWs. We have also examined the influence of the current density on the different groups of SiNWs in order to get an evaluation of the rate capability for each sample. Rates varying between $\mathrm{C} / 5$ and $5 \mathrm{C}$ have been applied. Fig. 4a displays the specific capacities vs. cycle number as a function of the lithiation/delithiation rate for the sam- ple with the smallest diameters. One typical charge/discharge cycle obtained for each rate are gathered in Fig. 4b-d respectively for samples 1, 2 and 3. For sample 1, the capacity of $3100 \mathrm{mAh} \mathrm{g-1}$ obtained for the first four cycles at $\mathrm{C} / 5$, is close to the theoretical one. It corresponds to $86 \%$ of the initial mass of silicon implied in the electrochemical processes, suggesting that an internal core made of csilicon is con- served during cycling, even if a tiny part is systematically involved in each new cycle. It can be thought that this crystalline framework further ensures good mechanical properties of the SiNWs. As long as it exists, available capacities do not decrease. Fig. 4a evidences that the lower the rate, the higher the avail- able capacities both in lithiation 
and delithiation processes. This result can be understood insofar as the lithium diffusion in the sili- con nanowire is the limiting process. Moreover, when the electron transfer becomes too fast, it can be thought that only the external part of the wire is involved in the electrochemical process, leading to a reduced capacity. Concerning electrochemical performances as a function of cur- rent density, small diameter SiNWs exhibit the best results with a specific alloying capacity decreasing from $\sim 4000 \mathrm{mAh} \mathrm{g}-1$ to $\sim 500 \mathrm{mAh} \mathrm{g}-1$ when the $C$ rate varies from $\mathrm{C} / 5$ to $5 \mathrm{C}$ (Fig. 4b). With samples 2 and 3 , although the charge-discharge profiles of galvanostatic curves are the same, the capacities obtained at $\mathrm{C} / 5$ rate are lower and the decrease is faster with the rate (Fig. 4c and d), so that with the largest diameters, no capacity is delivered at 5 C. Conversely, the high capacity value of $2000 \mathrm{mAh} \mathrm{g}-1$ achieved for sample at $1 \mathrm{C}$ rate (Fig. 4a), i.e. twice the capacity of samples 2 and 3 (Fig. $4 \mathrm{~b}$ and c) clearly outlines the interest of the small- est diameters. These results demonstrate the better rate capability provided by the use of small SiNWs diameter. The rate limiting pro- cess being Li diffusion, the small size of diameters promotes a more quantitative, more homogeneous and faster Li alloying-dealloying process. To check this assumption, the cyclability of small diame- ter SiNWs anode was investigated at $1.3 \mathrm{C}$ rate upon 50 cycles (Fig. 5a). The specific capacity for delithiation rapidly increases to reach a roughly stable capacity during the first 6 cycles up to $\sim 2900 \mathrm{mAh} \mathrm{g-1.} \mathrm{During} \mathrm{the} \mathrm{following} \mathrm{lithiation/delithiation} \mathrm{cycles,} \mathrm{only} \mathrm{a} \mathrm{weak} \mathrm{capacity} \mathrm{decay} \mathrm{is} \mathrm{observed,}$ revealing good capacity retention with still $2670 \mathrm{mAh} \mathrm{g}-1$ after 50 cycles. This capacity evolution vs. cycles at a high rate of $1.3 \mathrm{C}(\mathrm{j}=4.6 \mathrm{~A} \mathrm{~g}-1)$ is very close to that reported by Ruffo et al. [16] with an optimized potential range but at moderate rate only $\mathrm{C} / 5$ rate $(\mathrm{j}=0.84 \mathrm{~A} \mathrm{~g}-1)$. This finding clearly highlights the significant improvement of the rate capability provided by small diameter SiNWs. In other respects, the only one capacity values reported in literature at high rate, 1.6 C, are obtained for cycling experiments in a reduced potential range [11]. They are found to be much lower, by a factor two, than that reported in Fig. 5, for a same cutoff voltage of $0.15 \mathrm{~V}$. To our knowledge, $5 \mathrm{C}$ is a remarkable high rate for SiNWs that has never been reported in the literature
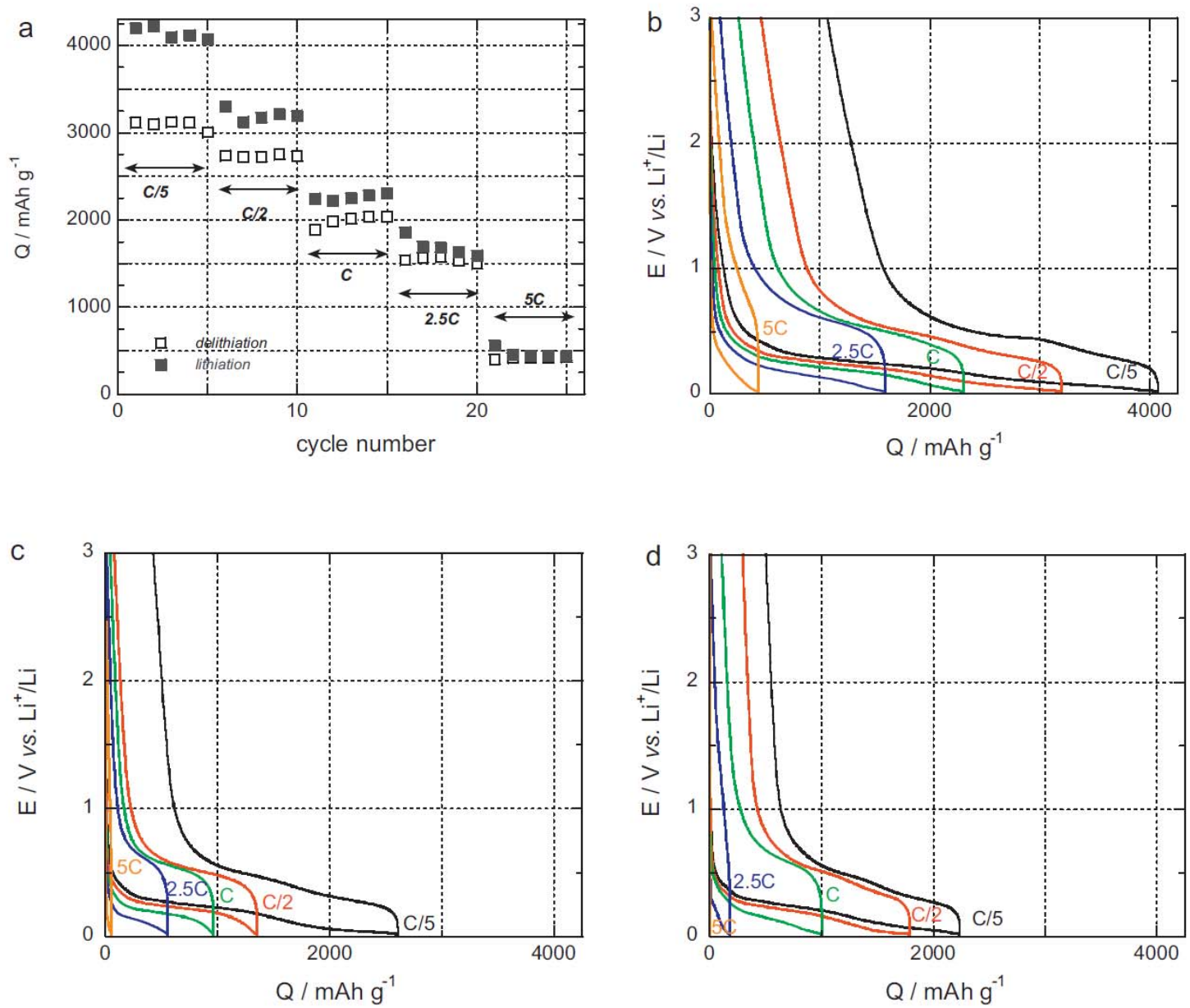

Fig. 4. (a) Influence of the current density, from C/5 to 5 C, on lithiation (black squares) and delithiation (white squares) for sample 1; (b), (c), (d) evolution of typical cycling curves with regime, respectively for sample 1 , sample 2 and sample 3. 

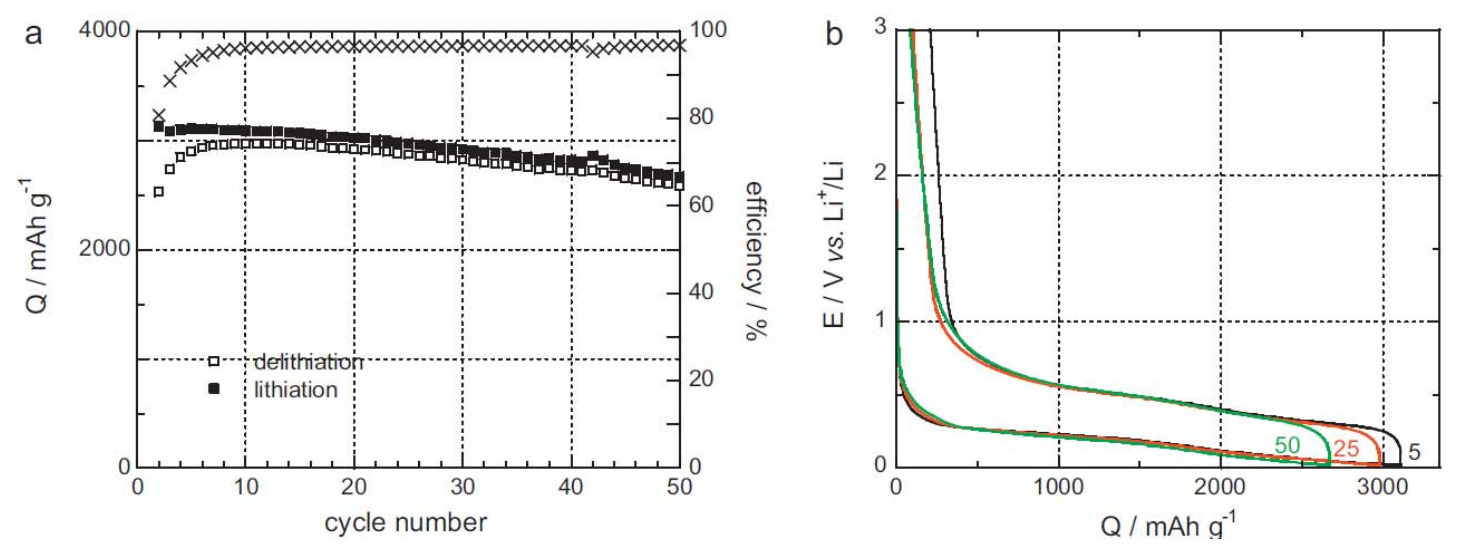

Fig. 5. (a) Lithiation (black markers), delithiation (white markers) and coulombic efficiency (crosses) of small diameter SiNWs (sample 1) vs. cycle number at $1.3 \mathrm{C}$ rate; (b) evolution of typical cycling curves corresponding to cycles 5, 25 and 50 .

\section{Conclusion}

Silicon nanowires present attractive properties as anode material in lithium-ion batteries and are widely studied. However, the role of SiNWs diameter size has been never addressed and in most cases not specified. Our SEM study and electro- chemical experiments show that the SiNWs diameter size and distribution constitute a crucial requirement for optimizing the charge-discharge properties. By tailoring the gold catalyst film thickness for SiNWs growth, we have demonstrated different diameters are obtained with a systematic distribution in diameter size and not a mean size value as usually reported in literature. For three gold thicknesses of 3, 10 and $30 \mathrm{~nm}, 80 \mathrm{wt} \%$ of the electroac- tive silicon consist respectively in wires with diameter size <65, 210 and $490 \mathrm{~nm}$. The capacity delivered by SiNWs has been proved to be dependent on the wires diameter: the smaller the diameter, the higher the capacity. For instance, at $\mathrm{C} / 10$ rate, values of 3500, 2700 and $2400 \mathrm{mAh} \mathrm{g-1}$ are respectively obtained in the second lithiation process for 65 , 210 and $490 \mathrm{~nm}$. The sample with smallest diameter values exhibits the best rate capability and can sustain high rates up to $5 \mathrm{C}$ with interesting capacities of 2500, 1500 and $500 \mathrm{mAh}$ g-1 at C, $2.5 \mathrm{C}$ and 5 C respectively. Such high capacity values for SiNWs at high rate have never been reported as yet. These results can be understood by the shorter diffusion pathway for lithium in SiNWs with small size diameter which ensures a fast and homogeneous lithiation. As a consequence, in the case of smallest diameters $(<65 \mathrm{~nm})$ we show an excellent cycle life with a stable capacity of $\sim 3000 \mathrm{mAh}$ g-1 at a relatively high rate $1.3 \mathrm{C}$. This first contribution to the understanding on how the morphology of silicon nanowires impacts their electrochemical performance clearly shows the need for a rigorous control of the SiNWs diameter during their growth. Therefore the use of an appro- priate template step must be the next step for further optimization.

\section{References}

[1] M.N. Obrovac, L. Christensen, Electrochem. Solid State Lett. 5 (2004) A93-A96. [2] J. Li, J.R. Dahn, J. Electrochem. Soc. 3 (2007) A156-A161.

[3] B.A. Boukamp, G.C. Lesh, R.A. Huggins, J. Electrochem. Soc. 4 (1981) 725-729. [4] J.P. Maranchi, A.F. Hepp, A.G. Evans, N.T. Nuhfer, P.N. Kumta, J. Electrochem Soc. 6 (2006) A1246-A1253.

[5] H. Jung, M. Park, Y.-G. Yoon, G.-B. Kim, S.-K. Joo, J. Power Sources 2 (2003) 346-351.

[6] S.H. Ng, J.Z. Wang, D. Wexler, K. Konstantinov, Z.P. Guo, H.K. Liu, Angew. Chem.Int. Ed. 41 (2006) $6896-6899$.

[7] Y. Yao, M.T. McDowell, I. Ryu, H. Wu, N.A. Liu, L.B. Hu, et al., Nano Lett. 7 (2011) 2949-2954.

[8] C.K. Chan, H. Peng, G. Liu, K. McIlwrath, X.F. Zhang, R.A. Huggins, et al., Nat. Nano 1 (2008) 31-35.

[9] B. Laik, D. Ung, A. Caillard, C.C. Sorin, D. Pribat, J.-P. Pereira-Ramos, J. Solid State Electrochem. 10 (2010) 18351839.

[10] B. Laïk, L. Eude, J.-P. Pereira-Ramos, C.S. Cojocaru, D. Pribat, E. Rouvière, Elec- trochim. Acta 17 (2008) 55285532.

[11] L.-F. Cui, R. Ruffo, C.K. Chan, H. Peng, Y. Cui, Nano Lett. 1 (2009) 491-495.

[12] K. Peng, J. Jie, W. Zhang, S.-T. Lee, Appl. Phys. Lett. 3 (2008), 033105-1-033105-3. [13] M.H. Park, M.G. Kim, J. Joo, K. Kim, J. Kim, S. Ahn, et al., Nano Lett. 11 (2009) 3844-3847.

[14] C.K. Chan, R.N. Patel, M.J. O’Connell, B.A. Korgel, Y. Cui, Acs Nano 3 (2010) 1443-1450.

[15] C.K. Chan, H.L. Peng, G. Liu, K. McIlwrath, X.F. Zhang, R.A. Huggins, et al., Nat. Nanotechnol. (2008) 31.

[16] R. Ruffo, S.S. Hong, C.K. Chan, R.A. Huggins, Y. Cui, J. Phys. Chem. C 26 (2009) 11390-11398.

[17] J.W. Choi, L.B. Hu, L.F. Cui, J.R. McDonough, Y. Cui, J. Power Sources 24 (2010) 8311-8316. 
[18] Y.J. Cho, H.S. Kim, H. Im, Y. Myung, G.B. Jung, C.W. Lee, et al., J. Phys. Chem. C 19 (2011) 9451-9457.

[19] R. Huang, X. Fan, W.C. Shen, J. Zhu, Appl. Phys. Lett. 13 (2009).

[20] K. Kang, H.S. Lee, D.W. Han, G.S. Kim, D. Lee, G. Lee, et al., Appl. Phys. Lett. 5 (2010) 3.

[21] Z. Wen, M. Cheng, J. Sun, L. Wang, Electrochim. Acta 1 (2010) 372-375. [22] M.N. Obrovac, L.J. Krause, J. Electrochem. Soc. 2 (2007) A103-A108.

[23] L. Baggetto, J.F.M. Oudenhoven, T. van Dongen, J.H. Klootwijk, M. Mulder, R.A.H. Niessen, et al., J. Power Sources 1 (2009) 402-410.

[24] C.K. Chan, R. Ruffo, S.S. Hong, Y. Cui, J. Power Sources 2 (2009) 1132-1140. [25] L. Chen, K. Wang, X. Xie, J. Xie, J. Power Sources 2 (2007) 538-543. 